\title{
im DETAIL
}

\section{Einfach Bauen Zwel}

nachhaltig

kostengünstig

lokal

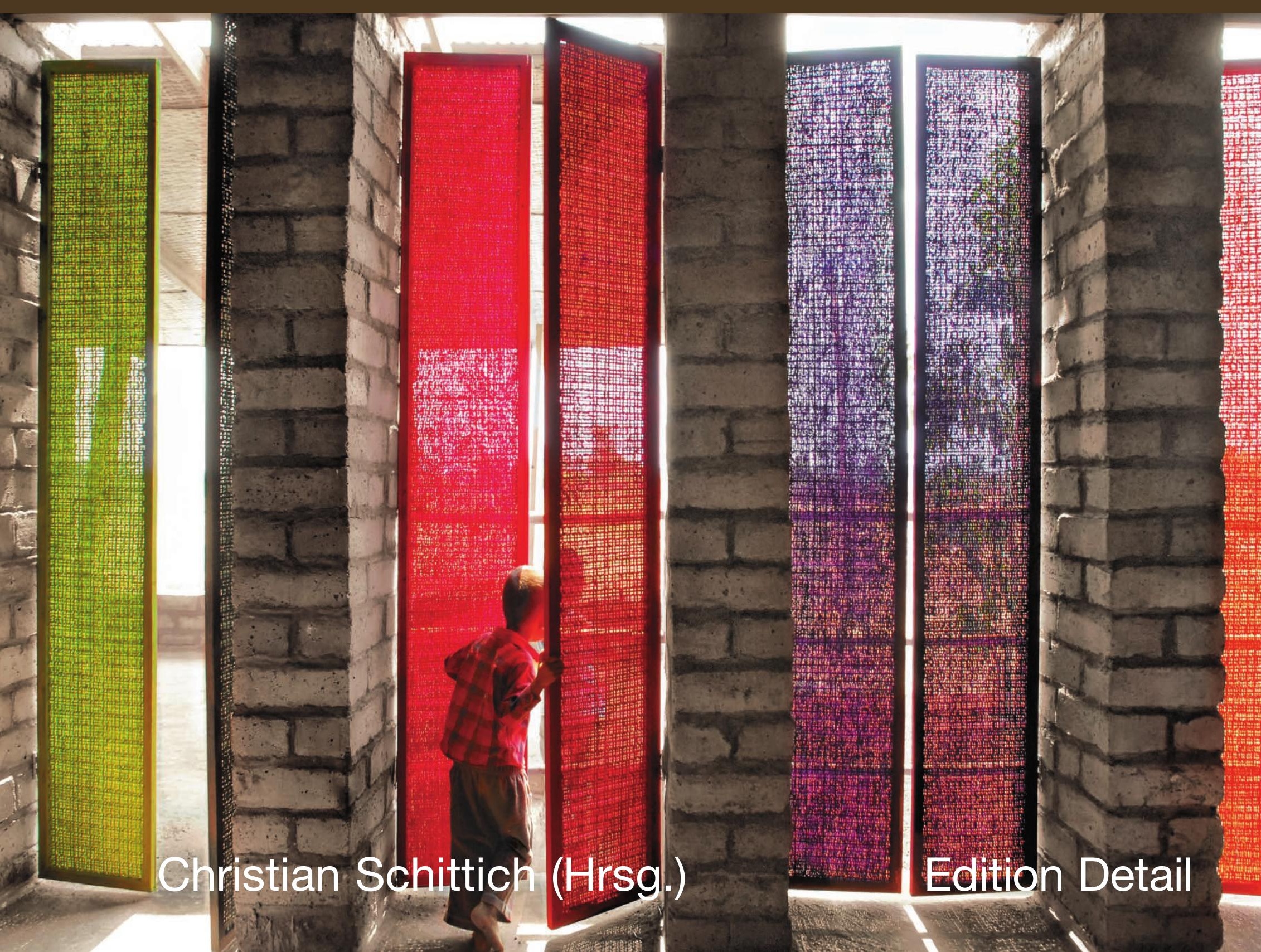




im DETAIL Einfach Bauen Zwei 


\section{im DETAIL \\ Einfach Bauen Zwei \\ nachhaltig \\ kostengünstig \\ lokal}

Christian Schittich (Hrsg.) 
Herausgeber: Christian Schittich

Redaktion: Steffi Lenzen (Projektleitung), Eva Schönbrunner, Melanie Weber Redaktionelle Mitarbeit: Katinka Johanning, Michaela Linder

Zeichnungen: Marion Griese, Martin Hämmel, Nicola Kollmann,

Emese M. Köszegi, Dejanira Ornelas

DTP: Simone Soesters

Ein Fachbuch aus der Redaktion DETAIL

Institut für internationale Architektur-Dokumentation $\mathrm{GmbH} \& \mathrm{Co} . \mathrm{KG}$

Bibliografische Information der Deutschen Nationalbibliothek

Die Deutsche Nationalbibliothek verzeichnet diese Publikation

in der Deutschen Nationalbibliografie; detaillierte bibliografische Daten

sind im Internet über

$<$ http://dnb.d-nb.de > abrufbar.

Dieses Buch ist auch in englischer Sprache erhältlich

(ISBN: 978-3-920034-67-6).

๑ 2012 Institut für internationale Architektur-Dokumentation GmbH \& Co. KG, Postfach 2010 54, D-80010 München

www.detail.de

Dieses Werk ist urheberrechtlich geschützt. Die dadurch begründeten Rechte, insbesondere die der Übersetzung, des Nachdrucks, des Vortrags, der Entnahme von Abbildungen und Tabellen, der Funksendung, der Mikroverfilmung oder der Vervielfältigung auf anderen Wegen und der Speicherung in Datenverarbeitungsanlagen, bleiben, auch bei nur auszugsweiser Verwertung, vorbehalten. Eine Vervielfältigung dieses Werks oder von Teilen dieses Werks ist auch im Einzelfall nur in den Grenzen der gesetzlichen Bestimmungen des Urheberrechtsgesetzes in der jeweils geltenden Fassung zulässig. Sie ist grundsätzlich vergütungspflichtig. Zuwiderhandlungen unterliegen den Strafbestimmungen des Urheberrechts.

Gedruckt auf säurefreiem Papier, hergestellt aus chlorfrei gebleichtem Zellstoff $(\mathrm{TCF} \infty)$.

Printed in Germany

Reproduktion:

Martin Härtl OHG, München

Druck und Bindung:

Kösel GmbH \& Co. KG, Altusried-Krugzell

ISBN: 978-3-920034-62-1

987654321 